\title{
The Mean Platelet Volume may not be Increased in Patients with Compensated Heart Failure
}

\author{
Cengiz Beyan ${ }^{1}$ (D), Esin Beyan² (1) \\ 'Department of Hematology, Ufuk University School of Medicine, Ankara, Turkey \\ ${ }^{2}$ Department of Internal Medicine, University of Health Sciences Keçiören Training and Research Hospital, Ankara, Turkey
}

Cite this article as: Beyan C, Beyan E. The Mean Platelet Volume may not be Increased in Patients with Compensated Heart Failure. JAREM 2018; 8(3): 207-9.

\section{Dear Editor,}

We reviewed the retrospective study of Yurtdaş et al. (1) titled "Investigation of neutrophil-lymphocyte ratio, platelet-lymphocyte ratio and mean platelet volume (MPV) in patients with compensated heart failure" with great interest (1). The authors stated that neutrophil-lymphocyte ratio, plateletlymphocyte ratio, and MPV values were significantly higher in patients with heart failure than in those in the control group. We would like to comment on this study because we believe that there are other factors that may affect the results of MPV in this study.

First, the authors state that MPV values are accepted as an indicator of platelet function and activation; however, currently, it is not accepted that platelet markers, including MPV, are indicators of platelet function. The gold standard technique for measuring platelet function is platelet aggregation, which is measured on the basis of light permeability, and studies that have used this techique to compare between platelet aggregation results and platelet markers, such as MPV, have found no relationship between the two $(2,3)$.

Noris et al. (4), in their review published in 2016, examined whether MPV measurements are of value in clinical practice. The authors reported that MPV measurements in real life cannot be determined as normal or increased because of reasons such as platelet count, sex, age, ethnic differences, and measurement methods that are still not standardized; therefore, they stated that MPV does not play a role in the diagnosis or prognosis of acquired diseases (4). It is of utmost importance that preanalytical variables of MPV measurement be considered while evaluating risk factors in various cases. In the whole blood count analyses conducted using the impedance tech- nology, the use of ethylenediaminetetraacetic acid as an anticoagulant significantly increases the MPV value. This change can be as high as 30\% in the first $5 \mathrm{~min}$ and 10\%-15\% more in the next $2 \mathrm{~h}$. Moreover, methods used for whole blood counts are also important in research, and measurement differences between the devices used in MPV measurements may vary up to $40 \%$. A meta-analysis study published in 2017 has examined researches on MPV published in the PubMed database since 2012 and reported that MPV measurements varied by $12.5 \%$ with respect to the time from blood collection to measurement, $17.8 \%$ with respect to the device used, and $27.7 \%$ with respect to both (5). Yurtdaş et al. (1), in their retrospective study, evaluated venous blood results obtained for blood count previously from all patients included in the study. However, in this study, the fact that the time from blood collection to measurement was unknown and devices used in the whole blood count and measurement methods were not mentioned make the validity of MPV data questionable.

In conclusion, MPV measurements contain significant standardization problems in retrospective studies. It is important that studies investigating the role of MPV in different diseases be conducted in large groups with prospective and standardized MPV measurements. Therefore, the result obtained in this study that MPV values increase in patients with compensated heart failure may not be reflected the truth.

Peer-review: Externally peer-reviewed.

Author Contributions: Concept - C.B., E.B.; Design - C.B., E.B.; Supervision - C.B., E.B.; Analysis and/or Interpretation - C.B., E.B.; Literature Search - C.B.; Writing Manuscript - C.B.; Critical Review - C.B., E.B.

Conflict of Interest: The authors have no conflict of interest to declare. 
Financial Disclosure: The authors declared that this study has received no financial support.

\section{REFERENCES}

1. Yurtdaş $M$, Özdemir M, Aladağ N. Investigation of neutrophil-tolymphocyte ratio, platelet-to-lymphocyte ratio and mean platelet volume in patients with compensated heart failure. JAREM 2018; 8: 67-71. [CrossRef]

2. Ho $\mathrm{CH}, \mathrm{Chan} \mathrm{IH}$. The influence of time of storage, temperature of storage, platelet number in platelet-rich plasma, packed cell, mean platelet volume, hemoglobin concentration, age, and sex on platelet aggregation test. Ann Hematol 1995; 71: 129-33. [CrossRef]

3. Beyan C, Kaptan K, Ifran A. Platelet count, mean platelet volume, platelet distribution width, and plateletcrit do not correlate with optical platelet aggregation responses in healthy volunteers. J Thromb Thrombolysis 2006; 22: 161-4. [CrossRef]

4. Noris P, Melazzini F, Balduini CL. New roles for mean platelet volume measurement in the clinical practice? Platelets 2016; 27: 607-12. [CrossRef]

5. Beyan C, Beyan E. Were the measurements standardized sufficiently in published studies about mean platelet volume? Blood Coagul Fibrinolysis 2017; 28: 234-6. [CrossRef]
Author's Response

\section{Author's Response: The Mean Platelet Volume May not be Increased in Patients with Compensated Heart Failure}

\author{
Mustafa Yurtdaş (D) \\ Clinic of Cardiology, Balıkesir Sevgi Hospital, Balıkesir, Turkey \\ ORCID ID of the author: M.Y. 0000-0002-0516-9206.
}

Cite this article as: Yurtdaş M. The Mean Platelet Volume May not be Increased in Patients with Compensated Heart Failure. JAREM 2018; 8(3): 207-9.

\section{Dear Editor,}

This letter is in response to the letter by Beyan, Cengiz, and Esin (2) referring to our article titled "Investigation of neutrophil-lymphocyte ratio, platelet-lymphocyte ratio, and mean platelet volume in patients with compensated heart failure" (1). We thank the readers for their interest in our article.

Platelets play an important role in inflammatory reactions and immune response and can be activated by various stimuli. Measuring platelet activity or function is time consuming, requires special devices, and is costly. Therefore, one of the most frequently used parameters to measure platelet activity is the mean platelet volume (MPV). MPV is known to be high in coronary artery disease and heart failure (3). The relationship between MPV and platelet activity or aggregation has been shown in some studies. Khaspekova et al. (4) have investigated the relationship between MPV and platelet aggregation and glycoprotein (gp) $2 \mathrm{~b} / 3 \mathrm{a}$ and $1 \mathrm{~b}$ content in healthy volunteers and patients with acute coronary syndrome. The results of the study showed that elevated MPV levels were associated with high platelet aggregation activity and enhanced gp $2 \mathrm{~b} / 3 \mathrm{a}$ and
$1 \mathrm{~b}$ expression. In another study investigating the relationship between MPV and various platelet activity measurements, MPV has been shown to be closely associated with some measurements of platelet activity, if not all (5). In some studies, the relationship between MPV and platelet aggregation or activity has not been shown to be sufficient. The most likely reason for this may be the low number of subjects in these studies. Because most studies that determined a predictive or prognostic value of MPV included a large patient population (3). Other possible causes may be the varieties of the disease, technique used, time of blood collection, and time of analysis. In the centers where our study was carried out, MPV was analyzed by impedance method. Blood samples were collected in ethylenediaminetetraacetic acid (EDTA) tubes and studied for 90-120 min in the same device. In addition, in our study, it was found that not only MPV was increased in patients with compensated heart failure but also other inflammatory markers, such as neutrophil-lymphocyte ratio, platelet-lymphocyte ratio, and high-sensitivity C-reactive protein (hsCRP) levels, significantly increased, and only the platelet-lymphocyte ratio predicted heart failure.

In conclusion, platelet activity is closely related to the pathophysiology of the underlying disease (such as thrombosis and inflammation). MPV is currently one of the cheapest and easily measurable parameters of platelet function. In fact, standardization is required for MPV measurements.

\section{REFERENCES}

1. Yurtdaş $M$, Özdemir M, Aladağ N. Investigation of neutrophil-tolymphocyte ratio, platelet-to-lymphocyte ratio and mean platelet volume in patients with compensated heart failure. JAREM 2018; 8: 67-71. [CrossRef]

2. Beyan C, Beyan E. The mean platelet volume may not be increased in patients with compensated heart failure. JAREM 2018; 8: 207-9. [CrossRef]

3. Sansanayudh N, Anothaisintawee T, Muntham D, McEvoy M, Attia J, Thakkinstian A. Mean platelet volume and coronary artery disease: A systematic review and meta-analysis. Int J Cardiol 2014; 175: 433-40. [CrossRef]

4. Khaspekova SG, Ziuriaev IT, lakushkin VV, Naimushin laA, Sirotkina OV, Zaitseva NO, et al. Mean platelet volume: interactions with platelet aggregation activity and glycoprotein IIb-IIIa and Ib exp- 
ression levels. Biomed Khim 2014; 60: 94-108. [CrossRef]

5. Shah B, Valdes V, Nardi MA, Hu L, Schrem E, Berger JS. Mean platelet volume reproducibility and association with platelet activity and anti-platelet therapy. Platelets 2014; 25: 186-90. [CrossRef]
Corresponding Author: Mustafa Yurtdaş,

E-mail: mustafayurtdas21@gmail.com

(C) Copyright 2018 by University of Health Sciences Gaziosmanpaşa Taksim Training and Research Hospital. Available on-line at www.jarem.org

DOI: 10.5152/jarem.2018.9206 